\section{Key Factors for Successful Implementation of Energy Efficiency Policy Instruments: A Theoretical Study and the Case of Latvia}

\author{
Reinis ABOLTINS ${ }^{1 *}$, Dagnija BLUMBERGA ${ }^{2}$ \\ ${ }^{1,2}$ Institute of Energy Systems and Environment, Riga Technical University, \\ Azenes iela 12/1, Riga, LV-1048, Latvia
}

\begin{abstract}
The success of energy efficiency policy depends on a number of factors, however, simultaneous application of more than just one policy instrument, coordination of multiple different policy instruments and a correct sequence of application of policy instruments are identified in research as three key factors related directly to policy making. Energy efficiency policy instruments are about the most appropriate ways of overcoming barriers to energy efficiency. The study adopts a policy analysis approach from social sciences to illustrate the relevance of a correct policy-making process in making energy efficiency policy effective. Analysis of interaction between the modules of decision-making matrix looks at the genesis of the faulty choice of energy efficiency policies. Studies of energy efficiency policy instruments indicate that implementation of a single separate policy instrument will most likely fail to achieve the expected results of overcoming barriers to energy efficiency and simultaneous implementation or combination of several policy instruments is preferable. If more than just one separate policy instrument aiming at improving energy efficiency is employed, then coordination in between two or more policy instruments as well as correct sequence of implementation of policy instruments is essential for achieving success. Lack of or insufficient attention to a full cycle of policy analysis leads to absence of one or more of the three key factors. Decision-making about energy efficiency policy instruments becomes faulty and is based on or influenced by ad hoc decisions and random circumstances, like, for example, availability or unavailability of EU financing. Such an approach contributes to maintaining or amplifying existing or creating new barriers to energy efficiency and leads to a new cycle of faulty decisions unless a proper process of policy analysis is applied in preparing and making decisions.
\end{abstract}

Keywords - Decision-making; energy efficiency; policy analysis; policy instruments; policy mix

\section{INTRODUCTION}

The notion of energy efficiency is generally applied to characterise a situation when processes of energy consumption can be optimised to an extent that allows using just minimum necessary amount of energy for the process to take place. Any energy not consumed to reach the desired result means that energy has been saved and used efficiently. The purpose of this publication is to demonstrate that a certain set of factors in decision-making and policy planning play a key role in achieving improved energy efficiency. The hypothesis therefore

\footnotetext{
* Corresponding author.

E-mail address: reinis.aboltins@ @rtu.lv 
is that the lack of a comprehensive policy analysis leads to faulty decisions and amplifies barriers to energy efficiency.

The article gives a brief overview of literature on the topic of barriers to energy efficiency and policy instruments that help to overcome or eliminate those barriers, lack of financing tools, lack of awareness, complex decision-making about renovation of residential buildings, low level of trust in ESCOs and financial institutions, inability to see long-term gains vis-à-vis investment being among the more common ones. Literature overview is followed by a description of methodology and description and analysis of the modules of the study prior to debating and drawing conclusions.

Decision-makers have to be able to "sell" energy efficiency, and energy efficiency has to be looked at in the context of market relations and ability of policymakers to prove the value of energy efficiency to the target audience with the goal to energise collective action [1], [2], which would lead to a comparatively large scale of energy efficiency activity [3]. Analysis of literature about policy instruments used to improve energy efficiency show that the most common mistake is trying to achieve the desired result by implementing only one policy instrument [2], [4] or having a too generalised approach to policy instruments [5] when it is important to be specific [6]. Sources, where efficiency of various energy efficiency policy instruments have been analysed, note that one of the most important messages to policy-makers and those who implement policy is that it is more essential how different policy instruments are being utilised together (simultaneously) to achieve the necessary amplifying effect [7], rather than which policy instruments per se policy-makers choose to implement [5].

Policy instruments shall preferably be used, which best suit the local market conditions [5] as such policy instruments will be best to overcome existing barriers and to strengthen also those market forces, which ensure achieving the desired result [8]. It is important in this context to identify and assess factors either hampering or fostering the efficiency of mutual interaction of energy efficiency policy instruments. These factors can be categorised in three big groups; those associated with the management mechanism of a policy instrument, the scope of a policy instrument and the time designated to the implementation of various policy instruments and simultaneous implementation of policy instruments [7].

Other authors distinguish between three big categories of policy instruments for enhancing energy efficiency - communication, economic and normative stimuli [9]. Most authors focus their analysis around slightly more detailed list of policy instruments; taxes associated with GHG emissions and energy consumption, subsidies, tradable and non-tradable allowances, technology standards, deposit or compensation systems, prohibition of certain products, voluntary agreements, investment by state authorities, and support to research and development [9]. Cialani and Perman identify seven different groups of policy instruments [10], which range from general education of target groups about the significance of energy efficiency to specific legally and financially binding solutions (see Table 1). 
TABLE 1. ENERGy EFFICIENCY POLICY INSTRUMENTS [10], [11]

\begin{tabular}{|c|c|}
\hline Category & Examples of instruments \\
\hline \multirow[t]{5}{*}{ Regulatory environment } & Building codes \\
\hline & Compulsory energy audits and energy consumption monitoring \\
\hline & Minimal energy consumption standards (MECS) \\
\hline & Energy consumption reduction targets \\
\hline & Energy efficiency investment obligation for private enterprises \\
\hline \multirow[t]{6}{*}{$\begin{array}{l}\text { Information, facilitation and market } \\
\text { transformation }\end{array}$} & $\begin{array}{l}\text { Energy consumption labelling (certificates) for buildings, vehicles and } \\
\text { devices }\end{array}$ \\
\hline & Smart metering and informative bills \\
\hline & Public information and facilitation campaigns \\
\hline & Inclusion of energy efficiency topics into school curricula \\
\hline & Education programmes and dissemination of knowledge \\
\hline & Labelling of electric devices and certification of buildings \\
\hline \multirow{2}{*}{$\begin{array}{l}\text { Commercialisation and capacity } \\
\text { building }\end{array}$} & Establishment of energy service companies (ESCO) \\
\hline & Development of energy efficiency sector \\
\hline \multirow[t]{3}{*}{ Technical support } & Energy audits \\
\hline & Project preparation tools \\
\hline & $\begin{array}{l}\text { Development and demonstration of application of energy efficiency } \\
\text { technologies }\end{array}$ \\
\hline \multirow[t]{9}{*}{ Financial instruments } & Subsidies for energy efficiency \\
\hline & Loans (subsidised or on beneficial terms and conditions) \\
\hline & Fiscal instruments (tax reductions, tax rebates) \\
\hline & Mandatory procurement for energy savings \\
\hline & Penalties for non-compliance with obligations or standards \\
\hline & Circular funds for investment in energy efficiency \\
\hline & Differentiated tariffs to discourage higher consumption \\
\hline & Grants for investment in energy efficiency \\
\hline & Direct purchasing / procurement of energy efficient goods and services \\
\hline \multirow[t]{3}{*}{ Cooperation instruments } & $\begin{array}{l}\text { Energy efficiency in public procurement including procurement of energy } \\
\text { efficient technologies }\end{array}$ \\
\hline & Purchase of goods and services through wholesale \\
\hline & Buy-back and recycling schemes \\
\hline Voluntary agreements & $\begin{array}{l}\text { Voluntary agreements about reduction of energy consumption and/or } \\
\text { investment in energy efficiency }\end{array}$ \\
\hline \multirow[t]{3}{*}{ Obligation schemes } & Supplier / distributor obligation schemes \\
\hline & Energy consumption reduction certificates (white certificates) \\
\hline & Investment of income from selling $\mathrm{CO}_{2}$ quotas in energy efficiency \\
\hline
\end{tabular}

When it comes to energy efficiency in the small and medium enterprise (SME) sector, different policy measures addressing industrial and service companies are usually categorised in two larger clusters - financial policy instruments and policy instruments associated with providing information, education and training [12].

The EU Energy Efficiency Directive (EED) (2012/27/EU) groups energy efficiency measures in seven clusters that highlight the key aspects of the EU energy efficiency policy, which is an essential part of the overall EU energy and climate policy [12]. 
1) Exemplary role of central government buildings

2) Purchasing by public bodies

3) Energy efficiency obligations and alternatives

4) Energy audits and energy management systems

5) Metering and billing information

6) Promotion of efficiency in heating and cooling

7) Energy transformation, transmission and distribution

Fig. 1. Clustering of the EU energy efficiency measures as derived from the Energy Efficiency Directive.

The EED builds on a broad spectrum of obligations and activities that will eventually contribute to improved energy efficiency, it does not focus on just one or a few sets of policy instruments rather taking an all-encompassing approach.

Specific types of policy instruments have gained special attention because of a potentially widespread application of these instruments. Mandatory obligation schemes are one such type of policy instrument and are regarded as a comfortable way to tackle efficiency of end use of energy. However, obligation schemes also have their risks and limitations; enterprises and utility companies vary in terms of field of work, their size, their capacity also depends on their position in the market and other factors, and there is also opposition to obligation schemes [13].

When it comes to energy efficiency, specifically in the industrial sector, the debate about interest of industry to invest is boiled down to balancing requirements with incentives and combining top-down and bottom-up approaches [2], which facilitate achieving energy efficiency targets in a cost-effective way [14] with a further debate on what role financial incentives [15] play in energy efficiency investment activity [16]. A simplified conclusion of the latter debate indicates that direct financial incentives boost activity in a short-term perspective while minimising activity in the longer term [17].

Although obligation schemes for utility companies represent a seemingly easy way to solve end user energy efficiency, gains and potential down sides should be analysed in the context of local market conditions prior to deciding to implement an obligation scheme for utilities [8]. The upside includes availability of own financing, existing cooperation with end users (go-to market, existing billing systems and energy consumption data), recognisability (provided the reputation is good), existing spectrum of services and delivery network (in respective license areas), responsibility for forecasting energy consumption and demand 
compensation. There are downsides, however - potentially low level of coincidence between commercial interests and interests of society, potentially low interest to increase costs and the cost of service or product or decrease sales. The International Energy Agency, which has produced a more broadly available analysis on energy efficiency policy instruments oriented towards decision-makers, emphasises that each situation deserves its specific analysis, but common elements and factors allow making generalisations and broadly applicable conclusions and suggestions about applicability of particular policy instruments [11].

\section{Methodology}

Policy analysis approach has been adopted from social sciences to tackle the hypothesis of this research. Sixteen modules are used in this analysis to describe the causalities and influences of different factors in making decisions about the choice of energy efficiency policy instruments and therefore achieving (or not achieving) improved energy efficiency in the country through higher activity and involvement of target groups.

The sixteen modules include:

1) Analysis of the current energy efficiency situation in Latvia (A);

2) Energy efficiency policy in the EU (C);

3) Identification and classification of barriers (B);

4) Analysis of causes of barriers (D);

5) Energy efficiency policy instruments in literature (E);

6) Sequence of energy efficiency measures $(\mathrm{J})$;

7) Choice and change of policy instruments (F);

8) Coordination of energy efficiency policies (I);

9) Simultaneous implementation of policy instruments $(\mathrm{H})$;

10) Policy instruments and measures $(G)$;

11) Policy review (K);

12) Assessment of the level of achievement (L);

13) Decision to terminate policy instrument (M);

14) Continuation of a policy instrument $(\mathrm{N})$;

15) Modification of a policy instrument $(\mathrm{O})$;

16) Introduction of a new policy instrument $(\mathrm{P})$.

The modules are categorised in four groups - input and output data modules (A, C, E and F), barrier identification and causality analysis modules (B, D), comparative modules for aligning three policy factors and policy instruments $(\mathrm{H}, \mathrm{I}$ and $\mathrm{J})$, and modules pertaining to policy review $(\mathrm{G}, \mathrm{K}, \mathrm{L}, \mathrm{M}, \mathrm{N}, \mathrm{O}$ and $\mathrm{P}$ ). The modules are further described to highlight their role in this analysis. 


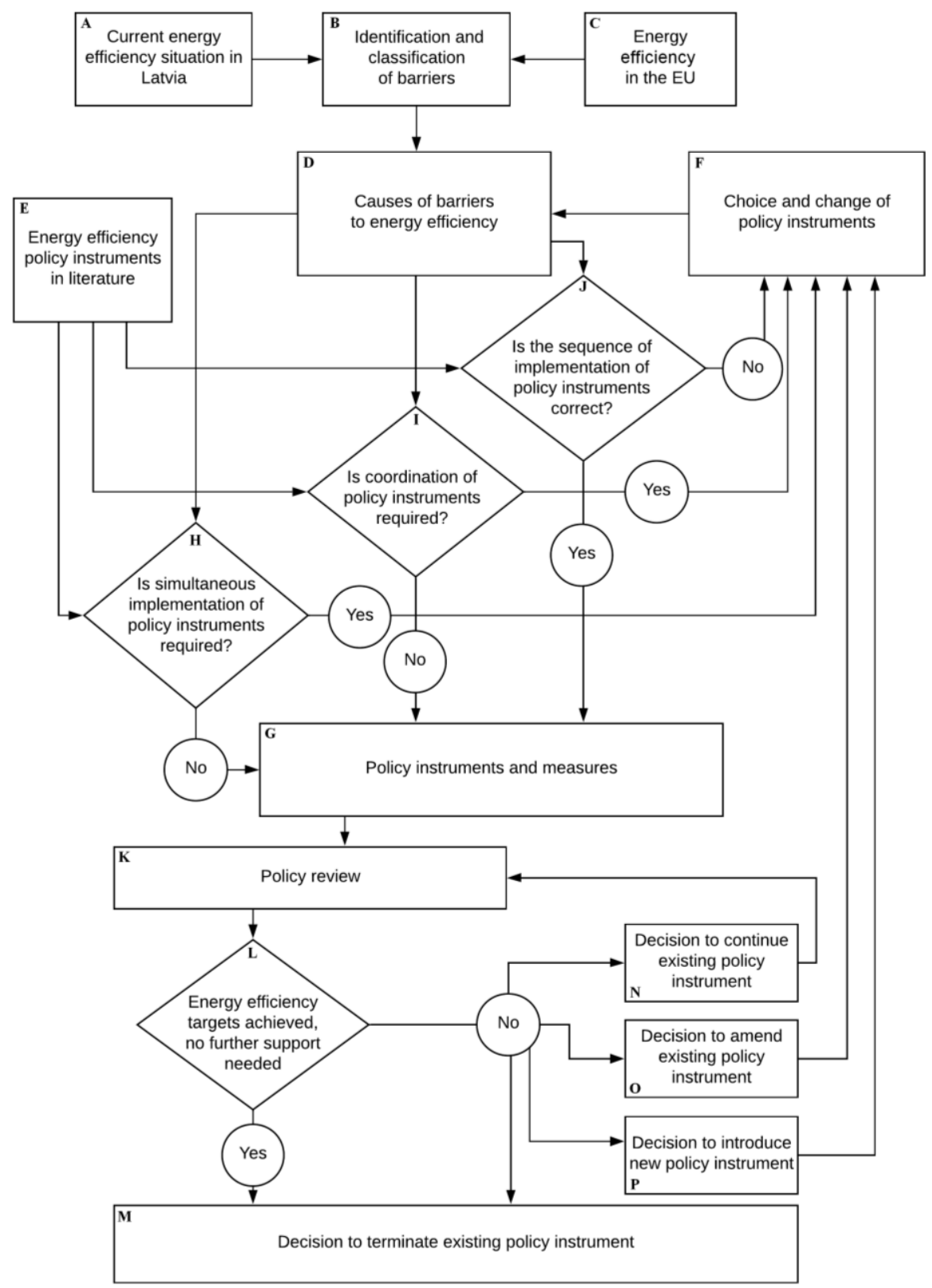

Fig. 2. Logical scheme of adopting decisions about energy efficiency policy instruments in the context of barriers to energy efficiency.

The scheme illustrates the processes connecting the modules, analysing whether the link between the modules exists and is strong enough to ensure that policy making about energy efficiency is carried out according to the principles of policy analysis. 


\subsection{Module A: Decision-Making on Energy Efficiency in Latvia}

One can look at energy efficiency on macro and micro level; on the macro level improving energy efficiency is about achieving national targets of reduction of energy consumption, while the micro level is about improving energy performance in multiple areas on an individual as well as collective scale. If targets are not set and goals achieved on the micro level, then overall goals will be compromised.

There is significant room for improvement when it comes to energy efficiency in Latvia. Ministry of Economics of Latvia has defined insulation of multi-apartment buildings, improving energy efficiency in public and industrial buildings, introduction of effective lighting infrastructure in municipal public space, increasing energy efficiency in heat production, improving energy efficiency in transport sector as the key policy directions and measures for achieving higher levels of energy efficiency [18], [19].

Although the situation varies between sectors (households, industry, services), progress is needed in all sectors. One of the key problems in making decisions about investment in energy efficiency in Latvia is insufficient local funding, insufficient choice of policy instruments related to financial incentives and reliance predominantly on availability of EU funds. The latter issue has been mentioned by experts in Latvia as particularly problematic as it amplifies the negative effects of the cyclic nature of the availability of funds - lack of energy efficiency activity when funds or grants are not available, high costs of energy efficiency and renovation works when funds are available due to increase in demand for construction services during the funding period playing a particularly negative role.

Energy efficiency level in households (apartment buildings, individual houses) can be described as not good, while the level of energy efficiency in industry can be assessed as average. The tertiary sector is the least motivated to invest in energy efficiency as many businesses are not owners of the buildings and have very little possibility to influence energy efficiency apart from technologies used to do their business. Any extra costs associated with high energy consumption are usually included in the price of the service or product (for example, offices that are used to serve particular businesses' clients).

Latvia's authorities responsible for energy efficiency (Ministry of Economics) are looking at energy efficiency measures through the prism of overall national energy efficiency goals stemming from the obligations and requirements of the EU Energy Efficiency Directive 2012/27/EU (EED), National Energy and Climate Plan and National Energy Efficiency Action Plan. Also, in 2018, as part of the Clean energy for all Europeans package, the new amending Directive on Energy Efficiency (2018/2002) was agreed to update the policy framework in view of 2030 and beyond. Yet in September 2019 it still remained to be seen how the approach of achieving common EU targets is going to influence national goals and ways to achieve the goals: the responsible authorities ought to formulate the final version of the National Energy and Climate Plan including detailed description of measures and policy instruments by the end of 2019. The goal is to create a national energy efficiency system, which would allow making energy savings in all areas of the energy sector - energy production, transmission and distribution, and end use. According to the EED, Latvia has an obligation to submit its indicative national energy efficiency target, which includes two mandatory components: Latvia has to ensure new savings of $0.8 \%$ of the annual final energy consumption annually by calculating these savings as the average over the three years before January 1, 2019 and annual renovation of $3 \%$ of the space of buildings owned by the state [18].

When it comes to apartments according to Eurostat data, Latvia ranks close to average energy efficiency in the EU-28 with energy consumption 1.41 toe per dwelling annually, which is just slightly above the EU average of 1.39 toe. The figure for Lithuania, Latvia's 
neighbour to the South, is 1.13 toe and for Estonia, Latvia's neighbour to the North, the figure stands at 1.48 toe per dwelling annually and can be regarded as average to the region. In terms of efficiency of space heating, Latvia with its 0.94 toe fits into the picture alongside such diverse company as France (0.94), Estonia (0.95 toe), Sweden (0.96 toe), Italy (0.96 toe), and the UK (0.96) [20].

More than 50 different barriers to energy efficiency were identified by experts in several consultation events in early 2019 and those are discussed further in the text. One observation stands out though - assessment of policy instruments and results has potential for improvement. Regular policy review has an important role, and a methodological approach to collecting, analysing, reporting and reviewing information on energy efficiency can significantly advance the information environment needed for a coherent energy policy planning, decision making and policy implementation ${ }^{\dagger}$.

\subsection{Module C: Energy Efficiency Trends in the EU}

EU has set energy efficiency targets to decrease energy consumption in all sectors. Energy efficiency levels vary among the EU member states, but the dominant trend is towards improvement of energy efficiency performance in all traditionally distinguished sectors households, industry and services. Policies employed in the EU member states have had some success; overall energy efficiency in terms of space heating has been steadily improving in the EU reaching 89.78 percent of the 1990 level in 2005 and 75.52 percent in 2016 [20].

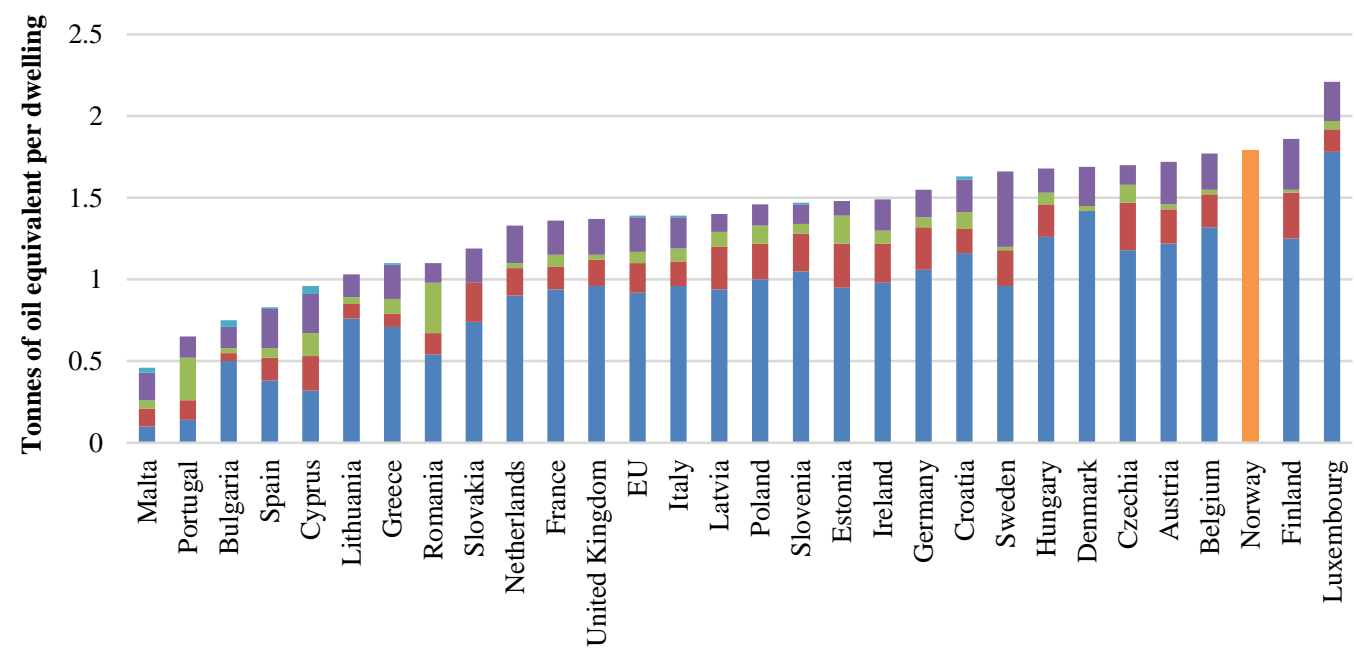

Space Heating $\quad$ Water heating $\quad$ Cooking $\quad$ Lighting and electrical appliances $\quad$ Cooling $\square$ Total

Fig. 3. Energy consumption by end use per dwelling in European countries (toe per dwelling) in 2016 [20].

When it comes to energy consumption for light and electrical appliances, economically more advanced countries consume more than the three Baltic States [21], [22] although this does not necessarily mean that there is a direct correlation between GDP and energy

† Two seminars on energy efficiency barriers and policy instruments were conducted by the Riga Technical University in March and April 2019. Over 50 barriers to energy efficiency were identified. Additional information about the workshop can be found at https://videszinatne.rtu.lv/category/energetika/ 
consumption. Decoupling of GDP and energy consumption is a reality which is explained by improved awareness about energy saving needs and gains as well as investment in improving energy efficiency while Latvia is investing little of its own money into energy efficiency measures thus currently keeping the trend that a growing GDP also means growing energy consumption.

While buildings in the EU account for circa 40 percent of final energy consumption, energy spending for buildings in the service sector amount to 46 percent [12]. This share is decreasing rapidly with improvement in the energy performance of buildings (51\% in 2005 against $63 \%$ in 1990). Energy used for information and communication technologies, and electrical appliances and lighting arrived in second position with a share of $39 \%$ in 2016. Cooking and water heating have a minor role and represent respectively $6 \%$ and $5 \%$ of this consumption. Cooling of buildings only represented $5 \%$ of energy consumption in the service sector (3\% in 1990) [20].

EU's Joint Research Centre has studied policies analysing National Energy Efficiency Action Plans (NEEAPs) and has concluded that funds, financial and fiscal measures, including taxes, have been used most frequently surpassing policy instruments associated with regulatory environment (laws, regulations, standards), which are among the second most used [23]. The adoption of the Energy Efficiency Directive has functioned as a relevant stimulus for EU member states to adopt policies, which would increase the pace of improving energy efficiency in all sectors.

\subsection{Module B: Identification and Classification of Barriers}

Barriers to energy efficiency are primarily related to three big groups of causes: 1) knowledge and information, 2) financing and 3) regulatory environment (laws, government regulations, rules, standards, no regulation vs overregulation, mandatory vs voluntary approach) [2], [24]. From the vantage point of authorities, it should be obvious that barriers are always a result of policy [25] and making decisions pertaining to energy efficiency [7]. This means that barriers can be remedied by terminating unsuccessful policy instruments and introducing new ones. It is thus up to authorities to engage policy analysts and researchers to provide alternatives and up to decision-makers to adopt policies, which would contribute to improving energy efficiency best.

Information and conclusions from three events have been used to analyse the case of Latvia. More than 50 barriers to energy efficiency were identified in three separate exercises with the involvement of energy efficiency and energy experts, representatives from municipalities, construction and building maintenance companies; 1) a closed workshop organised by the Riga Technical University (RTU) $\left.{ }^{\ddagger}, 2\right)$ an open workshop on energy efficiency by RTU with the participation of Pål Davidsen, system dynamics expert from the University of Bergen ${ }^{\S}$, and 3) annual Sustainable Energy Investment (SEI) Forum** organised by the Ministry of Economics and the European Commission on financing energy efficiency. The two events organised by the RTU were intentionally organised so that participants present their opinion about barriers to energy efficiency and policy instruments without prejudice or preliminary information from the organisers of the events. The two workshops organised by the RTU had the broadest possible approach to the subject, while the conference was dedicated specifically

\footnotetext{
\$arch 20, 2019, Riga Technical University.

$\S$ April 3, 2019, Riga Technical University.

** April 10, 2019, organised by the Ministry of Economics of Latvia, details available at https://ec.europa.eu/energy/en/topics/energy-efficiency/financing-energy-efficiency/sustainable-energy-investmentforums/second-roundtable-finance-energy-efficiency-10-april-2019-riga-latvia
} 
to the financial aspects of energy efficiency although without having a specific set of barriers to energy efficiency associated with financing presented to the participants. Thus, information from the participants was collected in a raw form and categorised by the authors of this article using a mix of typologies. The barriers identified by experts in the workshops belong to the entire spectrum of categories: there are internal and external barriers, barriers associated with knowledge, information, financing, market conditions, technical aspects, as well as regulatory environment [2].

One major observation from all three events is that regardless of the event and the target audience involved, conclusions about the barriers to energy efficiency coincide from one event to the other, as well as with sources of analysis on barriers to energy efficiency (see Fig. 4) [11], [26], [27]. Furthermore, the conclusions can be categorised and grouped according to the same principles, which is indicative of the similarity of the barriers as well as their causes. These similarities occur even though the local market conditions differ and set different stage for policy instruments to be implemented on. Thus, it can be claimed that classification of barriers and policy instruments is universally applicable and locally adaptable.

Barriers to energy efficiency and energy efficiency policy instruments to overcome barriers have been analysed in many studies and have been categorised in different ways. Researchers employ various approaches to categorising barriers and policy instruments and categorisation shall not be regarded as a limitation when analysing barriers - regardless of what categories are introduced the most appropriate policy instrument or instruments to tackle barriers has to be identified. There are a few most frequent ways to systematise barriers to energy efficiency and policy instruments to tackle the barriers [11], [26]-[28]. Fig. 4 represents a scheme of commonly accepted classification of barriers as well as policy instruments. Barriers are grouped in five larger clusters according to their nature and issues they are related to; barriers associated with information and knowledge, with financing, with market conditions, with technical factors and with institutional structure and regulatory framework. Policy instruments are grouped in seven bigger clusters, which stem from the logic of application of policy instruments and their association with certain types of barriers.

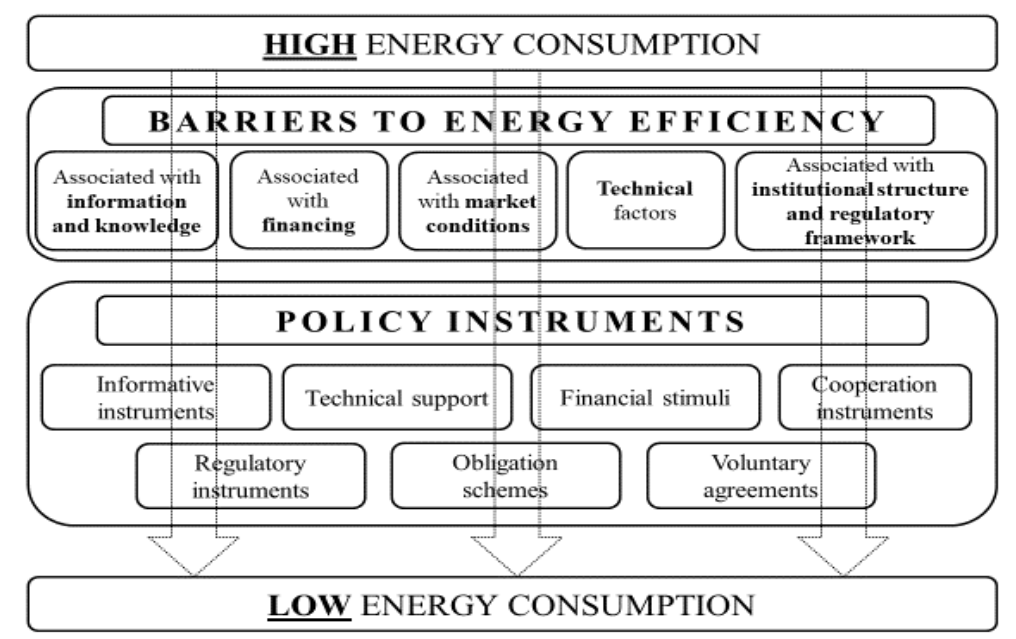

Fig. 4. Classification of barriers to energy efficiency and policy instruments (author's own illustration). 


\subsection{Module D: Analysis of Causes of Barriers}

There are factors that serve as a cause for various barriers to occur. These can be approached according to the typology established earlier for the purpose of the study.

Key causes of the barriers attributed to knowledge are lack of information, lack of knowledge about energy efficiency in general, lack of knowledge about energy efficiency measures, lack of willingness to get information, lack of willingness to learn about energy efficiency, lack of willingness to use knowledge. Some of the causes are related to behavioural issues like, for example, lack of motivation to use one's knowledge and information about energy efficiency to actually exercise action leading to improved energy efficiency. At the same time, although barriers associated with lack of or insufficient information and knowledge is regarded as one of the key problems in achieving mass scale of energy efficiency activity, it is argued that policy instruments to tackle these particular barriers have a low impact rate if exercised alone [1], [2], therefore they serve as auxiliary instruments in combination with other policy instruments [16].

When it comes to barriers pertaining to financing, one can distinguish between individual and collective levels of causes for barriers to occur. Typical causes on an individual level include lack of financial motivation to invest in energy efficiency, inability or lack of willingness to pay for energy efficiency measures [2], lack of trust and confidence in energy efficiency processes [24], lack of financial instruments to support energy efficiency activities in households [29]. On a collective level, there is lack of financial instruments that could trigger deployment of energy efficiency activities that would have mass character and would help to achieve not only individual but also country energy efficiency goals [24].

Several experts during the two workshops and the conference referred to earlier in the text noted that periodical availability of grants for energy efficiency that do not have to be repaid are good but have one important side effect - target audiences get used to getting a grant covering all needed investment and do not show any activity when generous grant mechanisms are not available, thus transforming a seemingly well-intended policy instrument into a serious barrier discouraging investment in energy efficiency [2], [7] when similar grants are not available and slowing down the process of improving overall energy efficiency level. Other kinds of financial instruments are regarded as a better and more effective choice compared to grant schemes as they tend to attract private financial resources and the money returned provides funds for future investment [4]. There is also another issue related to financial incentives: authorities tend to choose to employ policy instruments that are characterised by relatively simple technological solutions and low costs, thus contributing to further insufficiently complex and effective energy efficiency solutions [8]. Causes to such policy decisions might stem from lack of willingness to contribute to more fundamental improvements because of a number of factors and not least expectations to see and feel the result of investment timewise as close to the moment of investment as possible [2]. An aspect in favour of a less expensive step-by-step approach to energy efficiency measures however is the possibility to engage the private sector with financing on a project basis [30]. At the same time, providing targeted support to technology advancement and thus promoting fundamental changes in energy efficiency deserves more attention despite being a relatively costly policy approach [31].

The main cause of regulatory type of barriers is faulty policy and decision-making about factors affecting energy efficiency in one or another way. There can be various reasons behind poor decisions affecting energy efficiency, but one common reason is lack of analysis of barriers to energy efficiency, lack of modelling of scenarios followed by decision-making and implementation of policies that are not based on research, analysis and evidence. Lack of or 
insufficiently regular policy review can also contribute to faulty decision-making leading to implementation of wrong policy that does not allow to achieve the desired policy goals. Subsequently, failure of one policy instrument to achieve the desired results on its own may lead to a faulty conclusion that a policy instrument is useless and does not function [32].

As noted earlier, barriers to energy efficiency are consequences of decisions, except for the barriers associated with consumer behaviour and willingness to pay or other personal [de]motivators that are not related to any other factor. Decisions about policy instruments targeted to improve energy efficiency are related to first-time choices as well as decisions to change policy instruments [32]. If choices are based on limited or no analysis about the causes of barriers, there is risk that either erroneous decisions will be made or repeated feeding the loop of wrong choices and decisions will happen [33]. In the case of Latvia, more than 50 barriers to energy efficiency were identified by experts and this requires getting answers to the main questions - what are the causes of these barriers and have correct decisions been made when choosing and implementing policy instruments?

Knowing the causes of barriers questions ought to be asked about the three key factors that influence success of a policy instrument for energy efficiency:

1) Is the sequence of policy instruments correct?

2) Is coordination of policy instruments required?

3) Is simultaneous implementation of several policy instruments required?

As illustrated in Fig. 2, answers to these questions (represented in Modules H, I and J) feed into the Module F of choice and change of policy instruments that feeds into Module D of causes of barriers to energy efficiency. Alternatively, Modules H, I and J feed into \Module $\mathrm{G}$ of policy instruments and measures, which then requires regular periodic review (Module $\mathrm{K})$ to assess whether the chosen policy instruments that are being implemented deliver outputs that will allow to achieve the desired result (improved energy efficiency). Problems occur and persist in a system that lacks modules representing key factors $(\mathrm{H}, \mathrm{I}, \mathrm{J})$; choices end up having policy instruments and measures (Module $\mathrm{G}$ ), which are not best suited for achieving desired energy efficiency. The situation may get worse if policy review (Module K) does not take place and decisions about causes of underperformance and choice and change of policy instruments are dealt with based on insufficient analysis [33] or intuition thus contributing to maintaining existing or creating new barriers [9].

\subsection{Module E: Implementation of Energy Efficiency Measures: Building on Existing Analysis}

The decision-making scheme about energy efficiency barriers and policy instruments demonstrates the role of an external source of information and knowledge. Energy efficiency is not a new endeavour; therefore, it has been researched rather thoroughly including barriers and policies to overcome barriers [26], [34], [35]. It is the least resource consuming approach to study sources on empirical and theoretical studies on energy efficiency prior to making own decisions about policy instruments, the problem being that authorities responsible for policy planning tend to adopt decisions based on ad hoc principles [13].

One of the main conclusions of the study of literature on the relevant topic is that three factors play a key role in success in achieving energy efficiency goals: 1) sequence of implementation of policy instruments, if more than just one policy instrument is available over time, 2) simultaneous implementation of policy instruments, if more than one policy instrument is available, and 3) coordination of/between policy instruments, if more than one policy instrument is available [13], [32], [34], [36]. These factors are used in the model to demonstrate their role and effects on success of energy efficiency policy instruments. Backing 
for this conclusion is found further in this article when debating the role of modules of analysis.

In an ideal process, many elements, which are included in the model (see Fig. 2), have a specific role, and ignoring any one of these elements influences the rest of the system. For example, the situation in Latvia shows that energy efficiency activity (just as in construction sector in general) correlates with the availability of EU funds as the portfolio of energy efficiency policy instruments is relatively scarce. Thus, contribution to supplement the EU funds for energy efficiency activities is only one and typical policy instrument. Choice of other additional policy instruments is scarce and does not contribute to building synergies between a set of policy instruments. Gardner and Stern provide a solid research basis to a better understanding of how to approach energy efficiency policy making and turn peoples' attitudes, first, positive towards energy efficiency and, second, turn the positive attitudes into behaviour and actual action [2].

\subsection{Module J: Sequence of Energy Efficiency Measures}

Correct sequence of implementation of energy efficiency policy instruments in Latvia has been one of the factors having negative influence on overall energy efficiency. In fact, it is difficult to talk about a correct sequence of implementation of policy instruments as any sequence has depended on availability of resources/funding. Also, measures have been focused mainly on insulation works while, for example, deep renovation is a rare occurrence. Once again, picking the low-hanging fruit approach has dominated. One can say that the simplest measures are implemented mainly because of financial aspects: insufficient overall financing, fear to invest, long payback period, expensive to borrow money, very few ESCOs, lack of understanding of how energy efficiency financing works, etc. Scarcity of instruments that rely on availability of financing excludes applying a sequence of measures.

The principle of a correct sequence could be applied if additional or more than just one policy instrument would be available to support energy efficiency measures and policy instruments would be part of a set where one instrument complements another and there is certain logic behind introducing policy instruments in a particular order [7].

\subsection{Module H: Simultaneous Implementation of Policy Instruments}

One separate policy instrument can be successful given a certain set of conditions is present. Research literature presents indications that having only one policy instrument available to enhance energy efficiency is often not sufficient [15] and, more often than not, results in failure to achieve the desired result [7]. Simultaneous implementation of more than just one policy instrument or having a mix of policy instruments can significantly increase the chance of achieving not only the desired energy efficiency result [30] but can also have significant impact on deployment of innovative technologies [37] and solutions that contribute to mitigating climate change [38], resource efficiency [39] and social aspects by helping to address capacity of lower-income households to take part in energy efficiency activities [40]. However, it has also been argued that certain combinations of simultaneously enacted policy instruments can have mitigating rather than enforcing effects [7].

Effects of simultaneous implementation of policy instruments or interactions have been reviewed [5] looking at how interactions are defined and what criteria result in mitigating or enforcing capacity [7]. For example, financing for energy efficiency is essential, especially, when EU funds are available according to financing cycles. Lack of or insufficient own resources lead to a cyclic financing environment, which results in sharp drops in activity related to energy efficiency. Simultaneous implementation of alternative financing would 
complement the financial framework enforcing the effect of sufficient financial resources being available to target groups during the period when EU funds are not available. Therefore, according to the decision-making matrix (scheme), countries should plan their own budget for financing energy efficiency taking into consideration other financing sources to be able to counteract or balance the cyclic nature of external financing. In other words, counter-cyclic measures and policy instruments should be planned to keep energy efficiency activity stable if not linear throughout the period of time needed to achieve the desired energy efficiency results. It may be 10,15 or 20 years, which means that planning of energy efficiency policy instruments should have a long-term approach.

\subsection{Module I: Coordination of Energy Efficiency Policies}

Whenever more than just one policy instrument in support of energy efficiency is employed at the same time, some sort of coordination is necessary to maximise gains from two or more instruments and avoid a potential situation when policy instruments are implemented disregarding effects like competition between the measures or mitigating effects as discussed above [7] as well as loss of synergy effect that a better coordination of multiple policy instruments could bring [39].

The importance of coordination of energy efficiency policy instruments cannot be underestimated as it intertwines with simultaneous implementation of more than one policy instrument as well as correct sequence of implementation of two or more policy instruments. Coordination is especially important in a situation where there are numerous barriers to energy efficiency representative of all types - lack of knowledge and information, insufficient or no financial support, lack of regulatory incentives, market failures, absence of market-based instruments [41] or other. Numerous barriers require more than just one policy instrument to be overcome [7], [42] thus creating a situation where policymakers have to choose from a variety of policy instruments [17].

Most appropriate policy instruments to tackle specific barriers shall ideally be selected and implemented; a set of criteria (application of multi-criteria analysis) can introduce consistency in choosing a policy instrument and justifying the choice especially if it is related to influences on state or municipal budget. When elaborating on interactions of different policy instruments, Wiese has analysed those using criteria like effectiveness, static or dynamic efficiency, institutional requirements and governmental concerns, coming to conclusion that policymakers shall assess the interactions between policy instruments looking beyond direct impacts of combinations of policy instruments, as certain aspects relate to social and welfare influences. It has also been argued that factors like scope of the policy instrument, timing of implementation and steering mechanism shall be used to analyse interactions between policy instruments and their mitigating or enforcing effects [7].

\subsection{Module F: Choice and Change of Policy Instruments}

The choice of policy instruments shall be done firstly having carried out assessment of the situation in Latvia, experience in other countries and markets, being aware of the barriers to energy efficiency in Latvia, having modelled influences of various factors on achieving improvement in energy efficiency when it comes to scalable events/developments that already have or can potentially have significant impact on the overall energy efficiency performance of the country. The choice of new or change of existing policy instruments should take into account results of policy review aimed at establishing, which policies have succeeded in achieving better results and which have failed and need either to be terminated or amended [33]. Furthermore, policy mix or interaction between various policy instruments must be 
assessed ex ante if a new policy is being considered or ex post if existing policy has come to an end [43]. Success in overcoming existing barriers to energy efficiency must be analysed from the perspective of the three key factors - simultaneous implementation, coordination and sequence of implementation of policy instruments.

Policy review cluster (Modules $\mathrm{K}$ to $\mathrm{P}$ in Fig. 2) comes into play always when existing policy instruments need to be assessed the key point of reference being whether energy efficiency targets have been achieved and if further action is required to progress towards the desired results. Results of action taken within this cluster feeds input into the choice and change of policy instruments module (Module F) leading to new decisions that have to deal with causes of barriers. In theory, if steps in the scheme for adopting decisions on energy efficiency are not skipped, unsuccessful policy instruments will be terminated (Module M) or amended (Module $\mathrm{O}$ ) and will not reach the beginning of a new cycle of implementation of policy instruments.

If the desired results for improving energy efficiency are not achieved by employing one or more policy instruments, this shall be revealed by policy review and through comparing the situation with examples and studies in external sources of knowledge (Module E). Such a process should be sufficient for the purpose of effective policy making allowing at the same time to identify errors and solutions.

\subsection{Module G: Policy Instruments and Measures}

Analysis of factors causing barriers shall be carried out (using multi-criteria analysis or system dynamic) to eliminate or minimise barriers, and the most appropriate policy instruments for overcoming barriers under the particular energy efficiency market conditions shall be identified and implemented. Although policy instruments usually have to be prepared and adapted to a specific situation, environment, circumstances, generic policy instruments or generic sets of policy instruments exist that can be applied in almost any situation [44]. The question is whether analysis has been done to establish, which policy instruments are going to be best suited to achieve the desired energy efficiency results. According to the logical scheme of decision-making once the process has reached the module of policy instruments and measures (Module G), it is up to regular policy review [33] to monitor and assess success of policy instruments that are being implemented.

It is expected that energy efficiency policy instruments will be chosen by decision-makers according to the instruments' projected ability to tackle specific barriers. Furthermore, since there is a need to deal with numerous barriers, numerous policy instruments are needed, which entail the need for coordination of various policy instruments, the ability to identify a set of policy instruments [8] and the need to decide about the correct sequence of implementation of policy instruments [7]. Research sources indicate, however, that rational decision-making [29] about a combination of policy instruments is unlikely to happen in real life [5], and a set of policy instruments rather emerges than is deliberately decided upon since almost always there are political factors involved in decision-making [13] and knowledge of this shall be exploited to the benefit of achieving a better policy mix [11].

Typology of policy instruments has already been illustrated above when outlining the categories of barriers. Policy instruments that tackle barriers can also be categorised in other groups; those pertaining to the supply side and those pertaining to the demand side. Certain types of policy instruments can be attributed to both sides of the market, affecting both supply as well as demand side [41]. One can also elaborate on types of policy instruments further as those can be categorised as mandatory, voluntary or mixed [25], or as being price-based, quantity-based or having the form of obligation schemes [45]. Authors of this article have 
carried out an exercise of creating yet another scheme (Fig. 5), which may serve as grounds for building on the debate of creating policy mix for energy efficiency. Instruments represent the same clusters as indicated in Fig. 4 but have been slotted according to their role from the perspective of being related either to supply or demand side. The grouping of clusters has an illustrative nature as it visualises policy areas that are typically associated with measures on the supply and demand side, but also points to an area of policies where instruments overlap targeting both demand and supply side mostly through mixed and mandatory instruments. However, knowing policy instruments that "belong" to each of the seven clusters might direct policy-makers' thinking towards introducing combinations of policy instruments [15], which, when implemented simultaneously or launched in the correct sequence, have the potential to bring amplifying interaction or positive synergy to increasing energy efficiency activity [30] although risks of having mitigating [5] rather than amplifying effects [7] persist.

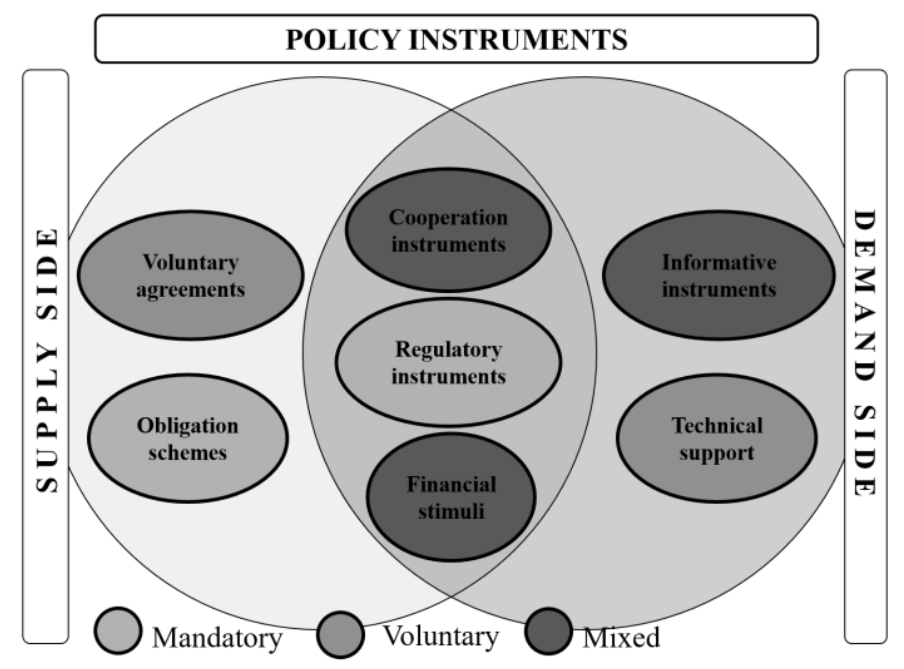

Fig. 5. Grouping of policy instruments depending on their relation to the supply or demand side (author's own illustration).

Still, the potential of all policy instruments must be assessed prior to pinpointing to instruments or a combination of instruments. According to the logical scheme of decision-making, this process has its place ideally at the beginning of the policy-making process (Module F) or, once decisions have been made, during a policy review (Module K). Regardless of what stage policy making is in, there are certain aspects to consider when deciding about policy instruments - relevance, impact of implementation, acceptance and consistent approach to implementation [7]. These aspects encompass analysing a broad range of issues [44] like barriers [9], mitigating and amplifying effects, availability of services, technologies [10] and financing [29], consumer behaviour, information and awareness [25] as well as compromises with other policy areas while competing for [often limited] resources [11]. 


\subsection{Module K: Policy Review and Deciding about Policy Instruments}

Regular policy review must be an essential element in the process of policy implementation. Policy review is part of policy analysis that allows assessing whether policy instruments that are being implemented are succeeding in achieving the desired result of the policy when policy was adopted, and allows making evidence-based decisions about terminating, continuing or amending existing policy instruments, or introducing new policy instruments instead of the terminated or in addition to existing ones [46]. Referring to classic policy analysis means that assessment of existing policy or policies have to be carried out not only before and after the planned period of implementation of a particular policy, but also at a set moment or several moments during the implementation of a policy.

Authors of this article suggest that a basic simplified approach to analysis of policy choices would involve at least measuring policy instrument's effectiveness (most positive impact with least cost) [47] and required urgency of action the latter having direct relation to actual physical condition of infrastructure and the rate of deterioration of this infrastructure if left unattended in terms of improving energy efficiency. Analysis would be expected to have been done already during the inception phase of policy making to avoid extra costs associated with need for major corrective actions if the chosen policy fails to achieve the desired results [33]. Alternatively, at least a simplified analysis shall be perceived as a must at the policy review stage (Module $\mathrm{K}$ in the decision-making scheme). In the context of the costs factor, Pikasa and others conclude that when deciding about major national approach to dealing with energy efficiency in buildings, ultimately the choice of policy instruments and general approach is narrowed down to two options - investing in renovation of buildings with minimum emphasis on energy efficiency and then losing energy and money or investing comparatively much more, do renovation in an energy efficient way and save resources and money owing to g ood energy efficiency [3]. Rosenow makes a similar observation noting that low complexity policy instruments dominate, but also emphasising that low cost and low complexity instruments are relevant to successful implementation of more complex and intrusive policy instruments associated, for example, with deep renovation of multi-apartment buildings instead of choosing simple measures [8].

As few energy efficiency policy instruments have been employed in Latvia thus far, it is particularly relevant to review the current approach to assess whether existing policy instruments have been satisfactory in achieving policy goals -improved energy efficiency. Low and slow uptake of energy efficiency measures in the housing sector indicates the lack of success of the chosen approach so far. It is preferable that a sector-by- sector assessment is carried out and conclusions drawn considering the proportional share of each sector in achieving the overall energy efficiency goals. There would normally be more than just one policy instrument to review and review might also involve deciding about introducing instruments, which correct errors created by past or existing instruments [9].

Policy review would normally result in one of four ways (as identified above) for each implemented policy instrument. If energy efficiency targets have been achieved and it is deemed that no further energy efficiency-specific policy instrument is needed (Module L), then a decision can be made about termination of the existing policy instrument (Module M). If energy efficiency targets have not been achieved yet, but analysis shows that a particular policy instrument is succeeding towards the set goal, a decision can be made to continue pursuing the existing policy instrument (Module $\mathrm{N}$ ) for a set period of time when the policy review shall be repeated again (Module K). If existing policy instrument indicates only partial success, then a decision can be made about amending the existing policy (Module O) to make it more successful in terms of achieving the desired result. Last, but not least, if any existing 
policy instrument has to be terminated for the reason that it did not work properly or the contribution of existing policy instruments was not sufficient enough to achieve the desired results, it can be decided to introduce a new policy instrument as a replacement or in addition to the existing one. A set of criteria can be used to assess whether a particular policy instrument has been or is still successful (for example, using a simple multi-criteria analysis, or system dynamic).

After this point, the decision-making flow feeds back to choosing and changing of policy instruments (Module F), which was the beginning of the initial loop. Decision-makers would be expected to make choices again based on the policy review results and their knowledge and information about barriers to energy efficiency, their causes and assessment of the three key factors influencing the success of adopted policy instruments referred to above simultaneous implementation, coordination and correct sequence of policy instruments.

\section{DiscuSSION AND CONCLUSIONS}

Policy making involves various types of environments and elements that range from rational and quantifiable to irrational, based purely on political will of participants of decision-making process at various stages and because of a multitude of reasons. Decision makers ought to try to rank the barriers and policy instruments to overcome the barriers trying to figure out priorities ideally stemming from results of multi-criteria analysis or system dynamics (Module G) analysis that allows ranking issues as part of a complete set of policy analysis processes and factors.

To avoid mistakes and costly errors, policy analysis must be factored into decision making about energy efficiency policy instruments. Also, using a combination of quantitative and qualitative analysis will produce the best results covering the diversity of aspects to be considered when deciding about the most appropriate policy measures. For the purpose of quantification of results of analysis, it is recommended that econometric and system dynamics models are used to analyse impacts of policies on the possibility to achieve the desired results (Module K). The ideal model would also exploit policy analysis, which focuses on determining the characteristics of issue to be analysed as well as the organisational and political setting of the issue [33]. Ignoring the context of processes may lead to dismissing factors, which contribute to creating and maintaining barriers to the desired policy results. Energy efficiency policy is no exemption to this rule.

A proper policy analysis requires time and resources to be conducted, but real life often creates pressure on decision makers to act fast because of certain conditions, like, for example, a need to make decision about allocation of funds that have become available or will not be available already soon. Priorities stemming from a democratic process of elections or voting for priorities may also appear to be a factor hindering correct process of making decisions. Energy efficiency is a long-term endeavour, but solutions that are long-term have a greater risk of getting deprived of a proper policy making process than solutions that apply short-term approach.

There are two main conclusions to this study. First, the three factors - simultaneous implementation of several policy instruments, coordination of several policy instruments and correct sequence of implementation of policy instruments within a mix - are crucial and their role in real-life decision making is often underestimated, leaving decisions to an ad hoc random chance. Second, adopting a decision about energy efficiency policy instruments is a complex problem. Policy analysis relevant to energy efficiency can be done through a swift process, which takes into consideration limitations set by real-life situations. Conditions are 
those related to any of the identified sets of instruments - financial, informative, regulatory, or other aspects affecting decision making can be factored into algorithms when preparing decisions about policy instruments. A study on practical application of knowledge of barriers, causes of barriers and policy instruments in relation to the involvement of multiple ene rgy efficiency stakeholders would benefit the process of making decision making algorithm a practical tool for policy makers.

\section{ACKNOWLEDGEMENT}

This research is funded by the Ministry of Economics of the Republic of Latvia, project "Energy and climate modelling towards net zero emissions", project No. VPP-EM-2018/NEKP_0001.

\section{REFERENCES}

[1] Blumberga A., Zogla G., Laicane I. Planning and Evaluation Tools for Energy Efficiency Policy in the Housing Sector in Latvia. Presented at the International Energy Program Evaluation Conference, Rome, Italy, 2012.

[2] Gardner G., Stern P. Environmental problems and human behaviour, $2^{\text {nd }}$ ed. Pearson Custom Publishing, Boston, 2002.

[3] Pikas E., et al. Quantification of economic benefits of renovation of apartment buildings as a basis for cost optimal 2030 energy efficiency strategies. Energy and Buildings 2015:86:151-160. doi:10.1016/j.enbuild.2014.10.004

[4] European Commission. Good practice in energy efficiency. 2017.

[5] Cunningham P., et al. Innovation policy mix and instrument interaction: a review. Manchester: University of Manchester, 2013.

[6] Plötz P., Fleiter T. Energy efficiency policies for different firm sizes: challenging current policies with empirical data. ECEEE 2012:347-354.

[7] Wiese C., Larsen A., Pade L-L. Energy Efficiency Policy: A Review of Instruments and Potential Interaction Effects. Presented at the 40th Annual IAEE International Conference, June 18-21, Singapore, 2017.

[8] Rosenow J., Kern F., Rogge K. The need for comprehensive and well targeted instrument mixes to stimulate energy transitions: The case of energy efficiency policy. Energy Research and Social Science 2017:33:95-104. doi:10.1016/j.erss.2017.09.013

[9] Blok K., et al. The Effectiveness of Policy Instruments for Energy-Efficiency Improvement in Firms. Springer Netherlands, 2004. doi:10.1007/978-1-4020-2157-2

[10] Cialani C., Perman, K. Policy instruments to improve energy efficiency in buildings. Dalarna: Dalarna University, 2014.

[11] International Energy Agency / OECD. Energy Efficiency Governance Handbook. Paris: OECD/IEA, 2010.

[12] European Commission. Clean Energy for All Europeans, 2019 [Online]. Available: https://ec.europa.eu/energy/en/topics/energy-strategy-and-energy-union/clean-energy-all-europeans

[13] Rosenow J., et al. Energy Saving Policies and Energy Efficiency Obligation Schemes. D5.1 Combining of Energy Efficiency Obligations and alternative policies. Oxford: University of Oxford, 2015.

[14] Rosenberg A., et al. Energy efficiency targets for industry - evaluating implementation options. Proceedings of the ECEEE Industrial Summer Study, 2012:305-310.

[15] Schlomann B., et al. Evaluation of Different Policy Instruments to Promote Industrial Energy Efficiency in a National Context. Proceedings of the ECEEE Industrial Summer Study, 2012:311-323.

[16] Schlomann B., et al. Energy Efficiency Trends and Policies in Industry: An Analysis Based on the ODYSSEE and MURE Databases. Fraunhofer ISI, 2014.

[17] Bordigoni M., et al. Forecasting white certificate flows with system dynamics. ECEEE Industrial summer study proceedings, 2016:5-15.

[18] Ministry of Economics of Latvia. National Energy and Climate Plan, 2018 [Online]. Available: https://ec.europa.eu/energy/sites/ener/files/documents/ec_courtesy_translation_lv_necp.pdf

[19] Ministry of Economics of Latvia. National Energy Efficiency Action Plan, 2017 [Online]. Available: https://ec.europa.eu/energy/sites/ener/files/documents/lv_neeap_2017_en_0.pdf

[20] European Environment Agency. Energy consumption by end use per dwelling, 2019 [Online]. Available: https://www.eea.europa.eu/data-and-maps/indicators/progress-on-energy-efficiency-in-europe-3/assessment (Fig. 3 illustrates energy consumption for space heating).

[21] Eurostat. Households consumption of electricity per capita, 2017 (MWh per capita). Available: https://ec.europa.eu/eurostat/statistics-

explained/index.php?title=File:Households_consumption_of_electricity_per_capita,_2017_(MWh_per_capita).png 
[22] Eurostat. Final energy consumption in households per capita, $\mathrm{kg}$ of oil equivalent. Available: https://ec.europa.eu/eurostat/tgm/graphCreator.do?tab $=$ graph $\& \mathrm{a}=0 \& \mathrm{cp}=$ noValue $\& \mathrm{c}=1 \& \mathrm{~d}=2 \& \mathrm{~h}=0 \&$ time $=0 \& \mathrm{y}=$ time \&geo $=2-39 \& \mathrm{x}=$ geo \&language $=$ en $\&$ pcode $=$ sdg_07_20\&plugin $=1$

[23] Economidou M., et al. Assessment of the Second National Energy Efficiency Action Plans under the Energy Efficiency Directive. Publications of the European Commission, 2018.

[24] Miezis M., et al. Climate Change and Buildings Energy Efficiency - the Key Role of Residents. Environmental and Climate Technologies 2016:17(1):30-43. doi:10.1515/rtuect-2016-0004.

[25] Bukarica V., Tomsic Z. Design and Evaluation of Policy Instruments for Energy Efficiency Market. IEEE Transactions on sustainable energy 2017:8(1):354-362. doi:10.1109/TSTE.2016.2599584

[26] Bertoldi P., Boza-Kiss B. Analysis of barriers and drivers for the development of the ESCO markets in Europe. Energy Policy 2017:107:345-355. doi:10.1016/j.enpol.2017.04.023

[27] Johansson M., Thollander P. A review of barriers to and driving forces for improved energy efficiency in Swedish industry - Recommendations for successful in-house energy management. Renewable and Sustainable Energy Reviews 2018:82(Part1):618-628. doi:10.1016/i.rser.2017.09.052

[28] Labanca N., Bertoldi P. Beyond energy efficiency and individual behaviours: policy insights from social practice theories. Energy Policy 2018:115:494-502. doi:10.1016/j.enpol.2018.01.027

[29] Markandya A., Labandeira X., Ramos A. Policy Instruments to Foster Energy Efficiency. Springer, 2015. doi:10.1007/978-3-319-03632-8 4

[30] Tromop R., et al. Best policy practices for promoting energy efficiency: a structured framework of best practices in policies to promote energy efficiency for climate change mitigation and sustainable development. United Nations Economic Commission for Europe, 2015.

[31] Bariss U., et al. System Dynamics Modeling of Households' Electricity Consumption and Cost-Income Ratio: a Case Study of Latvia. Environmental and Climate Technologies 2017:20(1):36-50. doi:10.1515/rtuect-2017-0009

[32] Kern F., Kivimaa P., Martiskainen M. Policy packaging or policy patching? The development of complex energy efficiency policy mixes. Energy Research and Social Science 2017:23:11-25. doi:10.1016/j.erss.2016.11.002

[33] Hogwood B. W., Gunn L. A. Policy Analysis for the Real World. Oxford: Oxford University Press, 1984.

[34] Rogge K. S., Reichardt K. Policy mixes for sustainability transitions: An extended concept and framework for analysis. Research Policy 2016:45:1620-1635. doi:10.1016/i.respol.2016.04.004

[35] Wilson C., Pettifor H., Chryssochoidis G. Quantitative modelling of why and how homeowners decide to renovate energy efficiently. Applied Energy 2018:212:1333-1344. doi:10.1016/j.apenergy.2017.11.099

[36] Helgesen P. I., Sandbakk M. Lessons learnt from 10 years of industry energy efficiency program management. Proceedings of the ECEEE Industrial Summer Study, 2012:137-147.

[37] Abeelen C. J., Both D. Energy efficiency measures: the next generation. Proceedings of the ECEEE Industrial Summer Study, 2012:93-100.

[38] Reinhilde V. Which policy instruments to induce clean innovating? Research Policy 2012:41(10):1770-1778. doi:10.1016/j.respol.2012.06.012

[39] Wilts H., O'Brien M. A Policy Mix for Resource Efficiency in the EU: Key Instruments, Challenges and Research Needs. Ecological Economics 2019:155:59-69. doi:10.1016/j.ecolecon.2018.05.004

[40] Schleich J. Energy efficient technology adoption in low-income households in the European Union - What is the evidence? Energy Policy 2019:125:196-206. doi:10.1016/j.enpol.2018.10.061

[41] International Energy Agency / OECD. Market-based Instruments for Energy Efficiency: Policy Choice and Design. Paris: OECD/IEA, 2017.

[42] European Commission. Directorate-General for energy, Good practice in energy efficiency for a sustainable, safer and more competitive Europe. Brussels: European Commission, 2017.

[43] Pereira G. I., Silva P. P. Energy Efficiency Governance in the European Union Member States - Analysis on current status. Assessment Methodologies Energy, Mobility and Other Real World Applications. Coimbra University Press, 2015:90-110. doi:10.14195/978-989-26-1039-9_4

[44] Klinckenberg F., Sunikka M. Better Buildings Through Energy Efficiency: A Roadmap for Europe. Brussels: EURIMA, 2006.

[45] International Energy Agency / OECD. Energy Efficiency 2018: Analysis and outlooks to 2040. Paris: OECD/IEA, 2018.

[46] European Commission. 2018 assessment of the progress made by Member States towards the national energy efficiency targets for 2020 and towards the implementation of the Energy Efficiency Directive as required by Article 24(3) of the Energy Efficiency Directive 2012/27/EU, Report from the Commission to the European Parliament and the Council, Brussels, 9.4.2019 COM (2019) 224 final. Brussels: European Commission, 2019.

[47] Vakulenko I., Myroshnychenko I. Approaches to the Organization of the Energy Efficient Activity at the Regional Level in the Context of Limited Budget Resources during the Transformation of Energy Market Paradigm. Environmental and Climate Technologies 2015:15:59-76. doi:10.1515/rtuect-2015-0006 